\title{
Sensoriamento remoto aplicado ao mapeamento do Cerrado no Norte de Minas Gerais e suas fitofisionomias
}

\author{
Remote sensing applied to cerrado mapping in the north of Minas Gerais and its \\ phytophysiognomies
}

\author{
Mariley Gonçalves Borges \\ Doutoranda em Geografia - Universidade Federal de Goiás, Brasil \\ marileigoncalvesborges@gmail.com
}

Hérick Lyncon Antunes Rodrigues

Mestre em Geografia - Universidade Estadual de Montes Claros, Brasil herick.lyncon.geo@gmail.com

Marcos Esdras Leite

Professor Dr. em Geografia - Universidade Estadual de Montes Claros, Brasil marcosesdrasleite@gmail.com

\begin{abstract}
Resumo
O Cerrado é fragmentado em fitofisionomias associadas às formações florestais, savânicas e campestres que apresentam características particulares e são classificadas de acordo com os estratos vegetais. Inserido nesse contexto, o sensoriamento remoto é uma ferramenta que permite identificar as características espectrais, espaciais e temporais de cada fitofisionomia, tornando possível constatar as alterações na paisagem dos Cerrados ao longo do tempo. Assim sendo, o objetivo deste trabalho foi analisar a ocorrência do Cerrado e suas fitofisionomias na mesorregião Norte de Minas Gerais. Este trabalho justifica-se pela necessidade de monitorar esse ecossistema que apresenta espécies vegetais endêmicas do Cerrado e com o crescimento do desmatamento, há risco de sua extinção. A metodologia utilizada consistiu em uma classificação supervisionada, usando o classificador Máxima Verossimilhança (Maxver), condições de bandas isoladas e vetorização de imagens, ambos realizados em softwares de geoprocessamento, tais como o ARC GIS 10.2 e ENVI 5.3. Como resultado, constatou-se que o Cerrado sentido restrito e a Mata Seca são as fitofisionomias dominantes na região. A ocorrência do Cerrado sentido restrito é em áreas aplainadas e elevadas e a Mata Seca ocorre em Fundos de Vale e em áreas de maior declividade. Têm-se também no Norte de Minas Gerais, áreas referentes a Campos Rupestres, Cerradão, Campo Limpo, Campo Sujo, Veredas, Mata Ciliar e Mata de Galeria. Essas fitofisionomias apresentam menores áreas e com exceção do Campo Rupestre, localizam-se em baixas altitudes do semiúmido.
\end{abstract}

Palavras-chave: Cerrado, fitofisionomias, sensoriamento remoto.

\begin{abstract}
The Cerrado is fragmented in phytophysiognomies associated with forest, savanna and pasture formations that present particular characteristics and are classified according to the vegetal strata. In this context, remote sensing is a tool that allows identifying the spectral, spatial and temporal characteristics of each phytophysiognomy, making it possible to verify the changes in the landscape of the Cerrados over time. Therefore, the objective of this work was to analyse the occurrence of Cerrado and its phytophysiognomies in the northern mesoregion of Minas Gerais. This work is justified by the need to monitor this ecosystem that presents endemic plant species of the Cerrado, and with the growth of deforestation, there is a risk of extinction. The methodology used consisted of supervised classification, using the Maximum Likelihood (Maxver) classifier, isolated band conditions and image vectoring, both performed in geoprocessing software such as ARC GIS 10.2
\end{abstract}


and ENVI 5.3. As a result, it was found that the Cerrado restricted sense and the Dry Forest are the dominant phytophysiognomies in the region. The occurrence of the restricted sense Cerrado is in flat and elevated areas, and the Dry Forest occurs in Vale Funds and areas of higher slope. There are also areas in the North of Minas Gerais, such as Campos Rupestres, Cerradão, Campo Limpo, Campo Sujo, Veredas, Mata Ciliar and Galeria Mata. These phytophysiognomies present smaller areas and, except for the Rocky Field, are located at low altitudes of the semi-humid.

Keywords: Cerrado, phytophysiognomies, remote sensing.

\section{INTRODUÇÃO}

Localizado no Planalto Central Brasileiro, o Cerrado é o segundo bioma brasileiro de maior extensão em área $\left(2.189 .169,62 \mathrm{~km}^{2}\right)$, somente ultrapassado pela Floresta Amazônica (KLING; MACHADO, 2005; RIBEIRO; WALTER, 1998). Este abrange os estados de Minas Gerais, São Paulo, Bahia, Goiás, Tocantins, Mato Grosso, Mato Grosso do Sul, Paraná, Maranhão, Piauí e o Distrito Federal (IBGE, 2004; SANO et al., 2008). No estado de Minas Gerais, aproximadamente $368.398,44 \mathrm{~km}^{2}(56 \%)$ de seu território é composto pelo bioma Cerrado (IBGE, 2004).

O Instituto Brasileiro de Geografia e Estatística - IBGE (2004) define bioma como uma área regional composta pelo agrupamento de espécies animais e vegetais, marcado pelo compartilhamento de histórias. Quanto às fitofisionomias do Cerrado, estas se relacionam às particularidades da vegetação (RIBEIRO; WALTER, 1998). A diversidade de nomenclatura das fitofisionomias existentes na literatura é muito vasta, como consequência há uma dificuldade em definir seus conceitos.

Autores como Ribeiro e Walter (1998) realizaram uma classificação fitofisionômica do Cerrado com base na análise da fisionomia vegetal, dos fatores físicos e da diversidade florística do Cerrado. Além do mais, é uma classificação regional, pertinente ao Cerrado e que possibilita o mapeamento da vegetação em escala de detalhes. As fitofisionomias do Cerrado destacadas por Ribeiro e Walter (1998) referem-se ao Cerradão, Mata Ciliar, Mata de Galeria, Mata Seca, Cerrado sentido restrito, Palmeiral, Parque de Cerrado, Veredas, Campo Limpo, Campo Sujo e Campo Rupestre.

O Cerradão é uma formação florestal de dossel contínuo, se localiza em solos profundos, com maior nível de acidez. A Mata Ciliar é definida como uma formação florestal composta por vegetação ripária que acompanha canais fluviais com maiores dimensões, quanto a vegetação ripária que compreende canais fluviais de menores dimensões, denomina-se de Mata de Galeria. A Mata Seca é a vegetação que ocorre em solos de maior fertilidade dos interflúvios, apresenta como principal característica a decidualidade. O Parque de Cerrado também conhecido como "Murundus" 
é composto por agrupamentos de vegetação que se localizam em áreas de pequenas elevações do relevo. O Palmeiral é a fitofisionomia do bioma Cerrado que apresenta como principal característica, a ocorrência de uma única espécie arbórea, o Palmeiral (RIBEIRO; WALTER, 1998).

O Cerrado sentido restrito é uma formação savânica composto por árvores, arbustos e herbáceas, sua principal área de ocorrência é em Latossolos. A Vereda é uma formação savânica composta pelo estrato herbáceo e arbóreo-arbustivo, possui como característica marcante a presença do buriti (Mauritia flexuosa). O Campo Limpo é uma formação campestre compreendida especificamente por herbáceas e o Campo Sujo é composto por herbáceas e arbustos, normalmente são encontrados em Litossolos e em Cambissolos. Quanto ao Campo Rupestre, este caracteriza-se pela presença de afloramentos de rocha, a vegetação é do tipo herbácea e arbustiva e sua localização são em áreas superiores a 900 metros de altitude (RIBEIRO; WALTER, 1998).

Destaca-se que o Cerrado é um bioma que tem passado por uma intensa supressão da cobertura vegetal em função das atividades de exploração econômica. Nesse sentido, para efeito de identificar, espacializar e monitorar as fitofisionomias do Cerrado, o sensoriamento remoto apresenta grande contribuição, uma vez que, permite obter informações dos objetos da superfície através da interação eletromagnética, sem haver necessidade de contato com os mesmos (ROSA, 2009). De acordo com Rosendo (2005) o sensoriamento remoto permite monitorar grandes áreas da superfície terrestre e comparar dados através do histórico de imagens de satélites.

Conforme Ponzoni, Shimabukuro e Kuplich (2012) o sensoriamento remoto aplicado a estudos de vegetação está totalmente associado à atividade fotossintética dos vegetais, dependendo da absorção da radiação eletromagnética e a sua reflectância dentro do espectro eletromagnético. Rosa (2009) acrescenta a morfologia e as funções físico-químicas das folhas como fatores que interferem no comportamento espectral da vegetação.

$\mathrm{Na}$ faixa do visível do espectro eletromagnético $(0,4 \mu \mathrm{m}-0,7 \mu \mathrm{m})$, a vegetação apresenta baixa reflectância, isso ocorre em função da absorção da radiação pela clorofila. No Infravermelho Próximo $(0,7 \mu \mathrm{m}-1,1 \mu \mathrm{m})$ há grande absorção da radiação pelas folhas e o consequente espalhamento interno, já na região do Infravermelho Médio $(1,1 \mu \mathrm{m}-3,2 \mu \mathrm{m})$ há a absorção da reflectância devido a presença da água na estrutura interna das folhas (PONZONI, SHIMABUKURO; KUPLICH, 2012).

Sobre o comportamento espectral dos solos, Rosa (2009) revela que está relacionado à quantidade de material orgânico presente no solo, da concentração de minerais, taxa de umidade e da composição química. Dentro do espectro, o comprimento de onda que há maior reflectância do solo é a faixa do Vermelho $(0,62 \mu \mathrm{m}-0,7 \mu \mathrm{m})$.

Quanto aos elementos que interferem no comportamento espectral da água temos os organismos vivos, as partículas orgânicas e inorgânicas, etc. No geral, a água apresenta baixa 
reflectância e alta absortância, no entanto, sua reflectância é mais elevada no comprimento de onda do Azul $(0,45 \mu \mathrm{m}-0,49 \mu \mathrm{m})$ e do Verde $(0,49 \mu \mathrm{m}-0,58 \mu \mathrm{m})$, isto é, no espectro visível.

Florenzano (2011) destaca que o comportamento espectral dos alvos depende de fatores como o nível e o método de aquisição dos dados, da geometria de visada, das condições ambientais e atmosféricas. Rosendo (2005) acrescenta o ângulo zenital, o vapor d'água, aerossóis, a estrutura do dossel, dentre outros. É importante ressaltar também, que para distinguir os diferentes alvos, a resolução espacial, espectral, temporal e radiométrica, exercem grande importância nos estudos que envolvem o sensoriamento remoto.

O Landsat é o principal satélite utilizado dentro do sensoriamento remoto na disponibilização de imagens gratuitas para estudos ambientais. Embora, sejam imagens de média resolução espacial, a série Landsat apresenta destaque devido seu histórico de cenas, uma vez que contribuem no monitoramento temporal da superfície. O primeiro satélite da série Landsat foi lançado no ano de 1972 pela National Aeronautics and Space Administration - NASA, o sistema Landsat tinha como objetivo "[...] a aquisição de dados espaciais, espectrais e temporais da superfície terrestre, de forma global, sinóptica e repetitiva” (ROSA, 2009. p. 97).

O satélite mais recente da série é o Landsat 8, este apresenta alterações na resolução radiométrica do sensor, foram incorporadas duas bandas multiespectrais, sendo a banda 1 - Coastal aerosol $(0.43 \mu \mathrm{m}-0.45 \mu \mathrm{m})$ e a banda 9 - Cirrus $(1.36 \mu \mathrm{m}-1.38 \mu \mathrm{m})$ com 30 metros de resolução espacial. No entanto, de todos os satélites lançados da série, o Landsat 5 se destaca devido ao maior período em órbita (1984 - 2011).

Nesse sentido, o objetivo deste trabalho é analisar por meio do sensoriamento remoto, a ocorrência do Cerrado e suas fitofisionomias na mesorregião Norte de Minas Gerais. Dessa forma, esta pesquisa se justifica pela necessidade de monitorar esse ecossistema, que apresenta desmatamento provocado pela expansão das atividades agrícolas. Com isso, espécies vegetais endêmicas do Cerrado são suprimidas, como o Caryocar brasiliense (pequizeiro), Hancornia speciosa (mangaba), Butia capitata (coquinho-azedo), Annona crassiflora (araticum), Eugenia dysenterica (Cagaita), Hymenaea courbaril (jatobá), gerando risco de extinção.

\section{MATERIAIS E MÉTODOS}

\subsection{Caracterização da área de estudo}

A mesorregião Norte de Minas Gerais localiza-se entre os paralelos de $14^{\circ} 24^{\prime} 0^{\prime \prime}$ e $17^{\circ} 33^{\prime} 0^{\prime \prime}$ de latitude sul e entre os meridianos de $41^{\circ} 56^{\prime} 0^{\prime \prime}$ e $45^{\circ} 44^{\prime} 0 "$ de longitude oeste de Greenwich. A região é constituída por sete microrregiões (Montes Claros, Salinas, Grão Mogol, Janaúba, Januária, 
Bocaiúva e Pirapora) perfazendo um total de 89 municípios distribuídos em uma área de 139.112,21 $\mathrm{km}^{2}$ (IBGE, 2010).

Composta pelo bioma Cerrado, Caatinga e Mata Atlântica, a região Norte de Minas apresenta 02 Reservas de Desenvolvimento Sustentável (Veredas do Acari, Nascentes Geraizeiras), 02 Reservas Biológicas (Serra Azul e Jaíba), 04 Áreas de Proteção Ambiental (Serra do Sabonetal, Pandeiros, Lajedão, Cochá e Gibão), 10 Parques Estaduais (Caminho dos Gerais, Lapa Grande, Montezuma, Grão Mogol, Lagoa do Cajueiro, Mata Seca, Serra das Araras, Serra Nova, Verde Grande e Veredas do Peruaçu) e 01 Parque Nacional (Cavernas do Peruaçu) - (Figura 1).

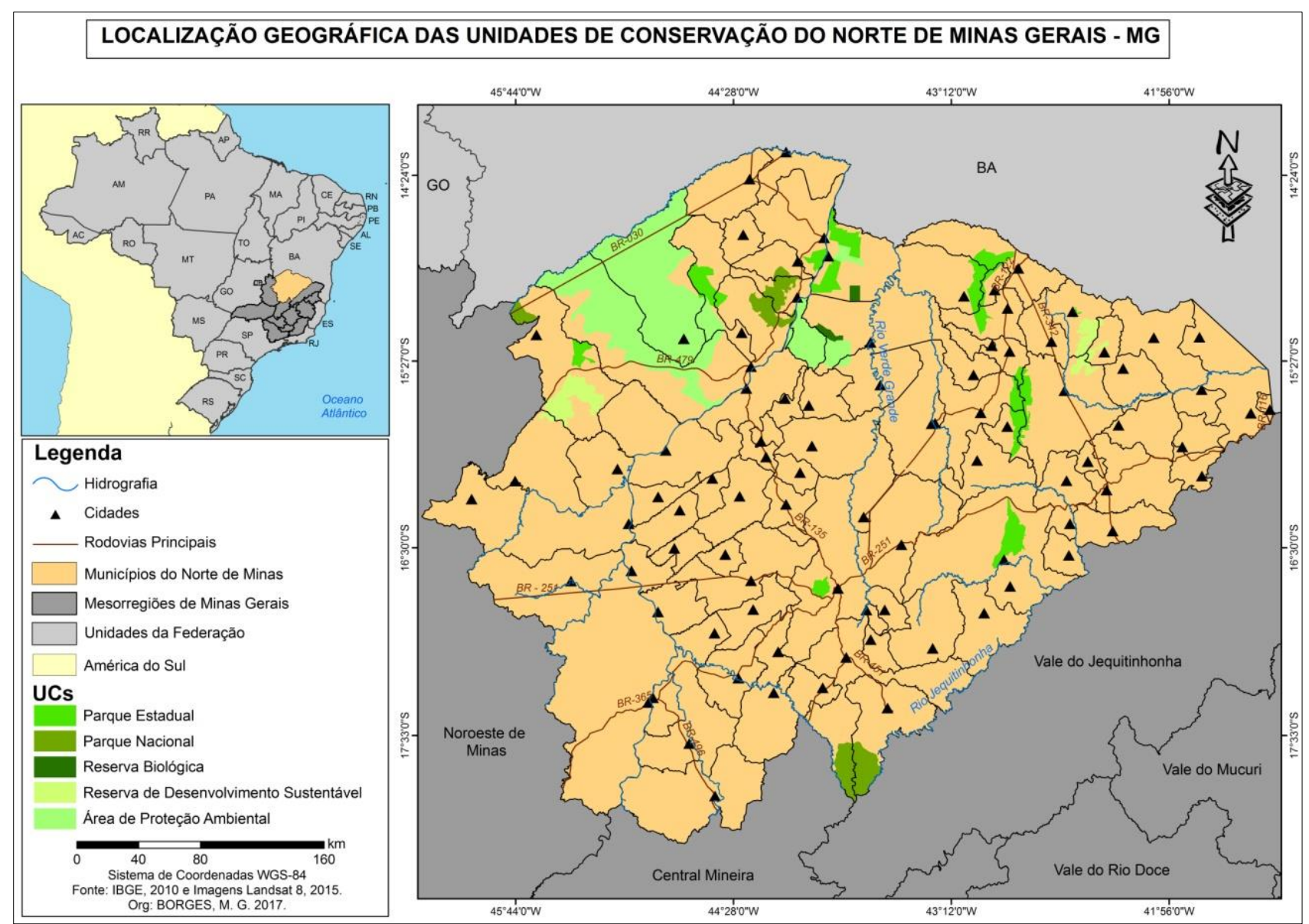

Figura 1 - Localização Geográfica das Unidades de Conservação do Norte de Minas Gerais.

Fonte: IBGE, 2010.

A região compreende três grandes bacias hidrográficas, sendo a bacia do Rio São Francisco, Rio Pardo e do Rio Jequitinhonha. Apresenta dois tipos climáticos, o semiúmido, com média de 4 a 5 meses secos durante o ano, e o semiárido, com média de 6 meses secos. Em ambos, a temperatura apresenta valores superiores a $18^{\circ} \mathrm{C}$ (IBGE, 2010). No geral, a pedologia da área é dinâmica, apresenta Neossolos (Flúvico, Litólico e Quartzênico), Latossolos (Vermelho, Amarelo e Vermelho-Amarelo), Argilossolos (Vermelho, Vermelho-Amarelo), Cambissolo Háplico e Gleissolo Háplico (IBGE, 2010). 
O Norte de Minas apresenta áreas com altitude de até 1797 metros. Desta forma, em áreas superiores a 700 metros têm-se a Serra do Espinhaço, Planalto dos Geraizeiros, Chapadas do Rio São Francisco, Chapadas, Planaltos e Patamares dos Rios Jequitinhonha/Pardo, Patamares dos Rios São Francisco/Tocantins e Serra da Saudade. Em altitudes inferiores a 700 metros, há as Depressões do Alto-Médio Rio São Francisco e Baixadas dos Rios Jacaré/Salitre e as Planícies Fluviais e/ou Fluviolacustres (SRTM, 2000; IBGE, 2010).

\subsection{Procedimentos Operacionais}

A fim de cumprir o objetivo proposto, realizou-se, primeiramente, uma revisão bibliográfica de autores que discutem sobre o Cerrado e suas fitofisionomias. Em seguida, adquiriuse as imagens do sensor OLI do Landsat 8 do Norte de Minas Gerais, através da plataforma digital da United States Geological Survey (USGS). As imagens obtidas são referentes ao inverno de 2015, e correspondem a órbita/ponto 217/71-72, 218/70-71-72, 219/70-71-72 e 220/70-71.

As bandas utilizadas correspondem ao comprimento de onda do Azul $(0.45-0.51 \mu \mathrm{m})$, Verde $(0.53-0.59 \mu \mathrm{m})$, Vermelho $(0.64-0.67 \mu \mathrm{m})$, Infravermelho Próximo $(0.85-0.88 \mu \mathrm{m})$, Infravermelho Médio 1 (1.57 - $1.65 \mu \mathrm{m})$ e Infravermelho Médio 2 (2.11 - $2.29 \mu \mathrm{m})$, ambas com 30 metros de resolução espacial. Em seguida, inseriu-se as cenas no software ENVI 5.3 e efetuou a composição espectral de imagens, o mosaico das cenas e o recorte da área de estudo.

Adiante, por meio da interpretação visual de imagens, realizou-se a identificação preliminar das classes que seriam abordadas e mapeadas neste trabalho. Tendo como base teórica a classificação fitofisionômica do Cerrado abordada por Ribeiro e Walter (1998), as fitofisionomias identificadas neste trabalho foram o Campo Limpo, Campo Sujo, Campo Rupestre, Cerrado sentido restrito, Cerradão, Mata Seca, Mata Ciliar, Mata de Galeria e as Veredas.

As áreas de Mata Seca e Cerrado sentido restrito foram as fitofisionomias que apresentaram a maior heterogeneidade de tonalidade e de estrutura. As formações antrópicas apresentam forma geométrica, textura lisa e localizam-se em áreas aplainadas. O Campo Limpo e o Campo Sujo confundem espectralmente com o solo exposto e a pastagem, o que necessitou de imagens de alta resolução espacial, como do WorldView-II, usadas neste trabalho, como suporte na distinção das classes.

As Veredas, a Mata Ciliar e a Mata de Galerias diferenciam-se pela dimensão e tamanho do canal. As Veredas em particular, podem também ser distinguidas da Mata Ciliar e da Mata de Galeria através de sua estrutura, uma vez que é composta por dois estratos, um arbóreo-arbustivo e outro herbáceo (RIBEIRO; WALTER, 1998). Além do mais, apresentam estrutura retilínea, com poucas curvaturas. Deve-se destacar que as áreas circundadas por fitofisionomias do tipo Mata Seca não apresentam a Vereda. 
Assim sendo, para efeito de delimitar o Cerrado sentido restrito, foi usada a Calculadora Raster do ArcGis 10.2 na criação de condições. Assim, considerou-se a Banda 4, Banda 5 e Banda 6, com níveis digitais superiores a 11000 e a Banda 3 com valores inferiores a 10000 como áreas de Cerrado sentido restrito.

As áreas correspondentes a Mata Seca foram identificadas por meio do Maxver e de condições de bandas isoladas. A condição na Calculadora Raster teve como base valores de números digitais iguais ou superiores a 8000 da Banda 2. O valor 8000 foi baseado na análise estatística de imagens e testes na Calculadora Raster, que por sua vez, apresentou a maior separabilidade entre classes.

O Campo Limpo e Campo Sujo foram identificados, mapeados e retirados da imagem por meio do Maxver. Com o auxílio das imagens WorldView-II separou-se as áreas de Campo Limpo das áreas de Campo Sujo, baseando-se nas características apresentadas por Ribeiro e Walter (1998). O Campo Rupestre foi extraído utilizando a álgebra do Infravermelho Próximo (NIR) com o Infravermelho Médio (MIR) considerando valores superiores a -0,012 e inferiores a 0,133 como áreas de Campo Rupestre.

Em seguida, usando a interpretação visual de imagens, fêz-se a identificação das áreas características de Veredas na imagem e com base na rede hidrográfica do IBGE (2010), em formato shapefile, selecionou a área aproximada de sua ocorrência. Em seguida, por meio da Calculadora Raster, usou-se a banda do Infravermelho Médio para identificar o estrato arbóreo-arbustivo e o Maxver para identificar o estrato herbáceo da Vereda. A Mata de Galeria e a Mata Ciliar foram delimitadas a partir de condições na Calculadora Raster utilizando o Infravermelho Médio como comprimento de onda principal em sua distinção.

Deve-se destacar que a delimitação das Veredas usando as imagens Landsat8 apresentaram restrições, uma vez que a resolução espacial das imagens (30 x 30 metros) impediram que atributos como o estrato herbáceo e arbóreo-arbustivo de algumas Veredas sejam visualizados, o que não possibilitou a delimitação. Desta forma, utilizou-se imagens WorldView-II, consideradas de alta resolução espacial, na identificação e delimitação da fitofisionomia Vereda no Norte de Minas Gerais.

Assim, a delimitação final das Veredas do Norte de Minas - MG foi efetuada manualmente, ou seja, a partir do processo de classificação visual, isto é, a vetorização, usando como base principal a imagem WorldView-II. Uma vez que, a delimitação das Veredas a partir do algoritmo classificador Maxver e das condições de bandas isoladas usando as imagens do Landsat8, identificamos uma área de 197,70 km², enquanto usando as imagens WorldView-II constatou-se cerca de $233,69 \mathrm{~km}^{2}$, diferença esta de $35,99 \mathrm{~km}^{2}$, isto é, $15 \%$. 
A Figura 2 (a e c - Landsat) e (b e d - WorldView-II) permite notar que a resolução espacial das imagens de satélite contribui ativamente na delimitação das Veredas do Norte de Minas Gerais. Pois, há casos que usando somente a imagem Landsat não é possível visualizar a Vereda, consequentemente, impossibilita sua delimitação.

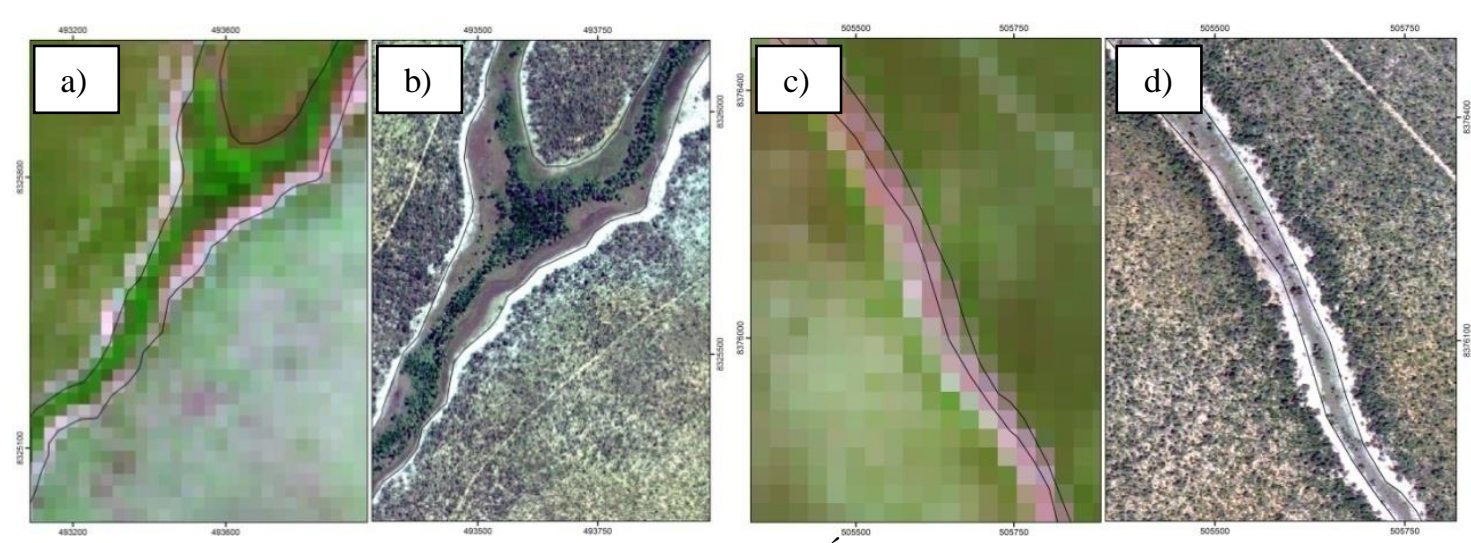

Figura 2 - Imagens Landsat8 e WorldView-II de Áreas de Veredas do Norte de Minas Gerais. Fonte: Imagens Landsat 8, 2015; Imagens WorldView-II, 2015.

Logo após todos os procedimentos citados,adquiriu-se gratuitamente o Modelo Digital de Elevação (MDE) da missão Shuttle Radar Topography Mission (SRTM), de 30 metros de resolução espacial, disponível no Portal da United States Geological Survey (USGS). As cartas utilizadas correspondem a 18S465ZN, 18S45ZN, 17S465ZN, 17S45ZN, 17S435ZN, 15S465ZN, 15S45ZN, 15S435ZN，15S42ZN,16S465ZN，16S45ZN，14S465ZN，16S435ZN，14S45ZN，16S42ZN e $14 \mathrm{~S} 435 \mathrm{ZN}$.

Em seguida, inseriu-as no software ArcGis 10.2, recortou a área de estudo e gerou a hipsometria do Norte de Minas Gerais. Este procedimento foi realizado com o objetivo de identificar as altitudes que predominam em cada fitofisionomia do Cerrado.

Obteve-se ainda, as variáveis físicas (geomorfologia e pedologia) do Norte de Minas Gerais no portal do Serviço Geológico do Brasil (CPRM) e os dados de clima no portal do Instituto Brasileiro de Geografia e Estatística (IBGE) e fez-se o cruzamento dos resultados obtidos via sensoriamento remoto com os aspectos físicos. Por último, as áreas foram quantificadas e espacializadas.

\section{RESULTADOS E DISCUSSÃO}

Utilizando Ribeiro e Walter (1998) como parâmetro na classificação fitofisionômica do Cerrado no Norte de Minas Gerais, tornou-se possível identificar e delimitar nove fitofisionomias. Dentre as formações florestais, identificou-se o Cerradão, a Mata Seca, a Mata Ciliar e a Mata de Galeria das formações savânicas, delimitou-se o Cerrado sentido restrito e a Vereda dentre as formações campestres, identificou-se o Campo Limpo, Campo Sujo e o Campo Rupestre. 
Todas as fitofisionomias da formação florestal e campestre foram identificadas, exceto da formação savânica (Parque de Cerrado e o Palmeiral). Uma vez que apresentam características muito específicas, como a localização em pequenas elevações do relevo. Outro fator que impediu a identificação das fitofisionomias Parque de Cerrado e do Palmeiral foi à limitação da resolução espacial das imagens de satélite e de radar.

O mapeamento gerado (Figura 3) mostra que as áreas de Cerradão encontram-se concentradas no leste e nordeste da mesorregião Norte de Minas Gerais. O Cerrado sentido restrito apresenta uma faixa contínua (nordeste, leste, sudeste, sul, sudoeste, oeste e noroeste), a exceção perfaz no extremo norte da região. Quanto à Mata Seca, esta concentra-se no extremo norte e sul do Norte de Minas Gerais e apresenta reentrâncias no leste, oeste, sudeste, sudoeste, nordeste e noroeste da região, especificamente em Fundos de Vale.

A Mata de Galeria acompanha os pequenos canais e córregos da região e a Mata Ciliar os canais fluviais maiores. As Veredas também acompanham os canais fluviais, no entanto diferenciam-se da Mata Ciliar e da Mata de Galeria, pois possuem o estrato herbáceo e arbóreoarbustivo, e a estrutura retilínea. Sua localização predomina no oeste da região, contudo, há, também, ao sul, leste, sudeste, nordeste e na área central do Norte de Minas Gerais.

Quanto ao Campo Rupestre, este se localiza em uma faixa contínua (sul, sudeste, leste, nordeste e norte) acompanhando especificamente a Serra do Espinhaço, e apresenta também áreas a sudoeste da região, mesmo que em menores proporções. O Campo Limpo e o Campo Sujo situamse na porção oeste da região Norte de Minas, à esquerda do rio São Francisco. O corpo hídrico é representado pelo rio São Francisco, perpassando a região Norte de Minas Gerais sentido norte-sul, pela barragem Bico da Pedra no município de Janaúba e pelo rio Itacambiruçu no município de Grão Mogol, ambos a leste da região.

Os usos antrópicos referem-se à pastagem, solo exposto, mancha urbana, silvicultura e cultivos (soja, café, algodão, etc.). A localização geográfica dos usos antrópicos dá-se em todo o Norte de Minas Gerais, predominando ao sul e extremo norte da mesorregião (Figura 3). 


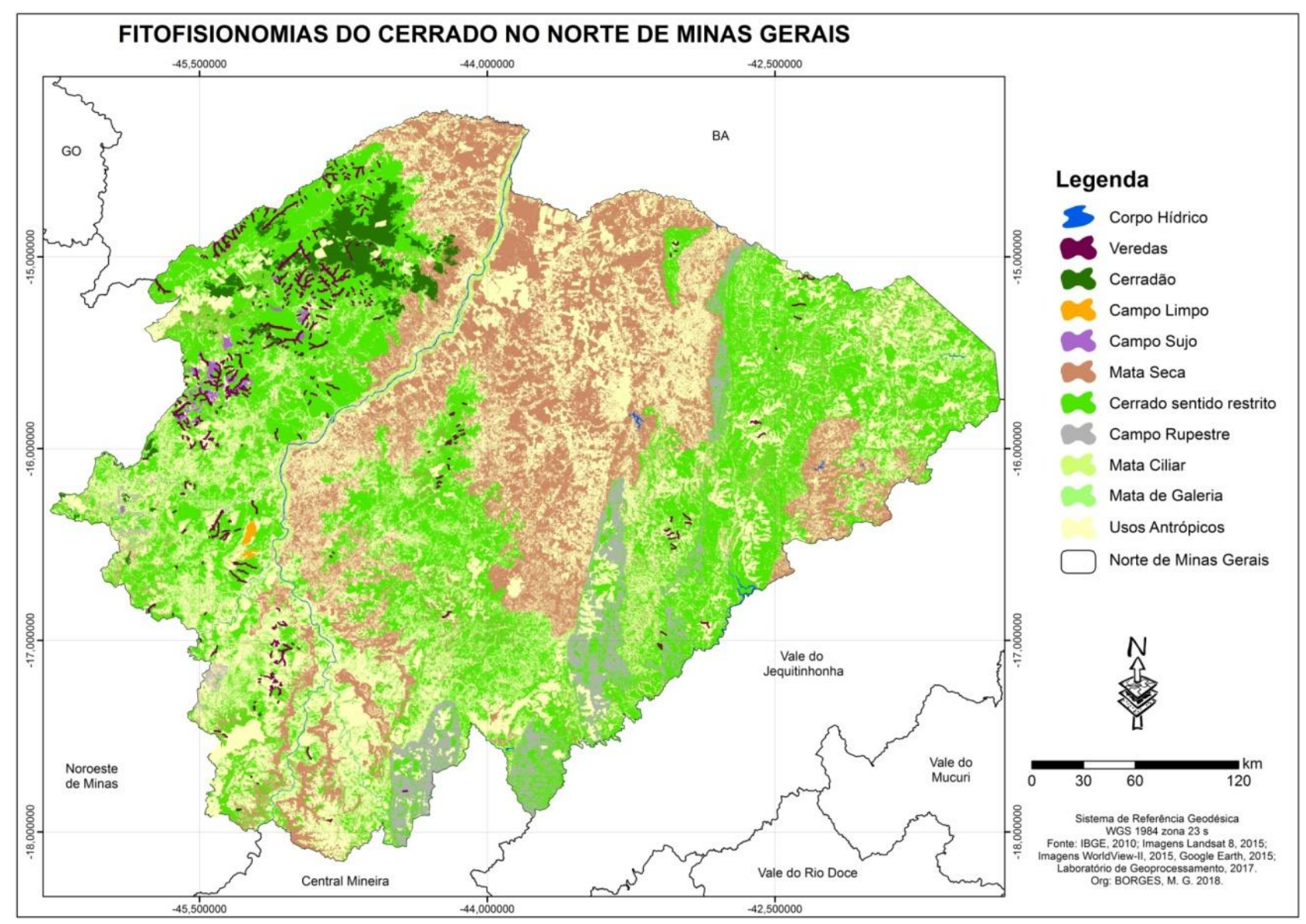

Figura 3 - Fitofisionomias do Cerrado no Norte de Minas Gerais.

Fonte: IBGE, 2010; Imagens Landsat 8, 2015; Imagens WorldView-II, 2015; Google Earth, 2015; Laboratório de Geoprocessamento, 2017.

Compreendendo 35\% do Norte de Minas, o Cerrado sentido restrito é a fitofisionomia que apresenta a maior área $\left(48.169,15 \mathrm{~km}^{2}\right)$. Encontra-se presente em 80 municípios, sendo Januária $\left(3.895,06 \mathrm{~km}^{2}\right)$, Bonito de Minas (2.860,14 km²), Buritizeiro (2.446,89 km²), Grão Mogol (2.311,28 $\mathrm{km}^{2}$ ), Rio Pardo de Minas (2.214,75 km²) e Chapada Gaúcha $\left(2.048,89 \mathrm{~km}^{2}\right)$, os municípios que possuem as maiores áreas desta fitofisionomia. Quanto aos municípios de Capitão Enéas, Catuti, Jaíba, Janaúba, Juvenília, Matias Cardoso, Nova Porteirinha, Pai Pedro e Verdelândia, estes não apresentaram áreas de Cerrado sentido restrito.

Situada principalmente no extremo norte da região, a Mata Seca abrange uma área de 28.346,18 $\mathrm{km}^{2}$, isto é 20,4\% do Norte de Minas Gerais. Embora apresente área inferior ao Cerrado sentido restrito, a Mata Seca encontra-se presente nos 89 municípios que constituem a mesorregião Norte de Minas Gerais. As maiores áreas estão localizadas em municípios como Jaíba (1.405,97 $\mathrm{km}^{2}$ ), Montes Claros $\left(1.312,61 \mathrm{~km}^{2}\right)$, Matias Cardoso $\left(1.203,38 \mathrm{~km}^{2}\right)$, Janaúba $\left(1.168,12 \mathrm{~km}^{2}\right)$, Manga $\left(1.149,74 \mathrm{~km}^{2}\right)$ e Francisco Sá $(1.109,10$ km²).

A Mata Ciliar apresenta uma área de $5.875,53 \mathrm{~km}^{2}$ e possui áreas mesmo que pequenas em todos os municípios do Norte de Minas. Sendo que os municípios que circundam o rio São Francisco apresentam as maiores áreas, como exemplo, cita-se os municípios de Januária (325,35 
$\mathrm{km}^{2}$ ), São Francisco $\left(225,46 \mathrm{~km}^{2}\right)$, Buritizeiro $\left(224,38 \mathrm{~km}^{2}\right)$, Pedras de Maria da Cruz $\left(199,45 \mathrm{~km}^{2}\right)$ e Manga $\left(199,45 \mathrm{~km}^{2}\right)$.

Diferentemente da Mata Ciliar, a Mata de Galeria apresenta uma área de 623,01 km² distribuídos apenas em 73 municípios. Uma vez que Capitão Enéas, Catuti, Espinosa, Gameleiras, Glaucilândia, Ibiracatu, Janaúba, Juramento, Mamonas, Matias Cardoso, Monte Azul, Pai Pedro, Patis, Porteirinha e Verdelândia não apresentaram áreas com resposta espectral de Mata de Galeria. As maiores áreas foram identificadas no município de Grão Mogol (54,74 km²), Salinas (53,95km²) e Rio Pardo de Minas (50,38 km²), localizados no leste da região.

Considerada a formação florestal com maior dificuldade de regeneração (AB'SABER, 2003) o Cerradão abrange uma extensão territorial de $2.670,01 \mathrm{~km}^{2}$, isto é $2 \%$ do Norte de Minas Gerais. É encontrado em 12 municípios da região, a saber: Bonito de Minas, Buritizeiro, Chapada Gaúcha, Cônego Marinho, Itacarambi, Januária, Miravânia, Montalvânia, Riachinho, Santa Fé de Minas, São João das Missões e Urucuia. Estes municípios em que há a presença de Cerradão estão todos localizados na margem esquerda do rio São Francisco.

Presente em 23 municípios (Botumirim, Buritizeiro, Bocaiúva, Cristália, Espinosa, Francisco Dumont, Francisco Sá, Grão Mogol, Guaraciama, Itacambira, Juramento, Lassance, Mato Verde, Monte Azul, Olhos D'água, Porteirinha, Riachinho, Rio Pardo de Minas, Santa Fé de Minas, Santo Antônio do Retiro, São Romão, Serranópolis de Minas e Várzea da Palma) o Campo Rupestre engloba uma área de $4.510,89 \mathrm{~km}^{2}$, equivalente a $3 \%$ do Norte de Minas.

Assim sendo, conforme o mapeamento efetuado, as fitofisionomias do Cerrado que apresentam as menores áreas foram o Campo Sujo, Veredas e o Campo Limpo. O Campo Sujo abarca uma área total de $372,55 \mathrm{~km}^{2}$ e situam-se apenas em 5 municípios. A maior área encontra-se presente no município de Chapada Gaúcha $\left(227,59 \mathrm{~km}^{2}\right)$, seguido por Urucuia $\left(56,43 \mathrm{~km}^{2}\right)$, Bonito de Minas $\left(42,31 \mathrm{~km}^{2}\right)$, Januária $\left(37,94 \mathrm{~km}^{2}\right)$, e por último, temos o município de Riachinho $(8,28$ $\left.\mathrm{km}^{2}\right)$.

As Veredas são encontradas em 27 municípios do Norte de Minas e abrangem uma área total de 233,69 $\mathrm{km}^{2}$. Os municípios de Bonito de Minas $\left(70,73 \mathrm{~km}^{2}\right)$, Januária $\left(49,26 \mathrm{~km}^{2}\right)$, Chapada Gaúcha $\left(35,47 \mathrm{~km}^{2}\right)$, Urucuia $\left(18,14 \mathrm{~km}^{2}\right)$ e Buritizeiro $\left(12,57 \mathrm{~km}^{2}\right)$ destacam-se com as maiores áreas - (Tabela 1). Em sua totalidade, são aproximadamente 439 Veredas distribuídas na região, a maior quantidade de Veredas são encontradas em Buritizeiro (90), Bonito de Minas (87), Januária (57), Chapada Gaúcha (43), Cônego Marinho (35), Urucuia (26), Montalvânia (19), São Romão (18), Grão Mogol (9), São João da Ponte (9), Santa Fé de Minas (8) e São Francisco (6). Quanto ao Campo Limpo, este apresentou a menor quantidade de áreas $\left(103,63 \mathrm{~km}^{2}\right)$ e encontra-se presente em apenas dois municípios (Santa Fé de Minas e São Romão). 
Tabela 1 - Fitofisionomias do Cerrado por Municípios do Norte de Minas em km².

\begin{tabular}{|c|c|c|c|c|c|c|c|c|c|}
\hline $\begin{array}{l}\text { Municípios do } \\
\text { Norte de Minas }\end{array}$ & Veredas & Cerradão & $\begin{array}{c}\text { Cerrado } \\
\text { sentido } \\
\text { restrito } \\
\end{array}$ & $\begin{array}{l}\text { Mata } \\
\text { Seca }\end{array}$ & $\begin{array}{c}\text { Campo } \\
\text { Rupestre }\end{array}$ & $\begin{array}{c}\text { Mata } \\
\text { de } \\
\text { Galeria }\end{array}$ & $\begin{array}{l}\text { Mata } \\
\text { Ciliar }\end{array}$ & $\begin{array}{l}\text { Campo } \\
\text { Limpo }\end{array}$ & $\begin{array}{c}\text { Campo } \\
\text { Sujo }\end{array}$ \\
\hline Águas Vermelhas & - & - & 847,52 & 13,18 & - & 3,58 & 32,93 & - & - \\
\hline Berizal & - & - & 335,09 & 12,41 & - & 3,16 & 14,57 & - & - \\
\hline Bocaiúva & - & - & 1785,28 & 147,81 & 521,84 & 42,73 & 159,2 & - & - \\
\hline Bonito de Minas & 70,73 & 724,45 & 2860,15 & 52,03 & - & 10,93 & 94,03 & - & 42,31 \\
\hline Botumirim & 2,24 & - & 1064,18 & 40,71 & 232,46 & 28,05 & 72,42 & - & - \\
\hline Brasília de Minas & - & - & 787,16 & 175,6 & - & 3,79 & 47,3 & - & - \\
\hline Buritizeiro & 12,57 & 4,87 & 2446,9 & 1021,68 & 89,96 & 11,27 & 224,38 & - & - \\
\hline Campo Azul & - & - & 153,87 & 177,52 & - & 0,83 & 18,5 & - & - \\
\hline Capitão Enéas & - & - & - & 686,67 & - & - & 26,71 & - & - \\
\hline Catuti & - & - & - & 111,98 & - & - & 6,64 & - & - \\
\hline Chapada Gaúcha & 35,47 & 33,01 & 2048,89 & 134,03 & - & 17,34 & 89,13 & & 227,59 \\
\hline Claro dos Poções & 0,55 & & 318,39 & 73,93 & - & 2,48 & 28,72 & - & - \\
\hline Cônego Marinho & 6,03 & 799 & 602,51 & 132,11 & - & 3,52 & 32,95 & - & - \\
\hline Coração de Jesus & - & - & 1293,21 & 326,85 & - & 2,82 & 82,03 & - & - \\
\hline Cristália & - & - & 661,61 & 15,51 & 26,02 & 19,46 & 30,86 & - & - \\
\hline Curral de Dentro & - & - & 357,54 & 28,76 & - & 4,16 & 19,22 & - & - \\
\hline Divisa Alegre & - & - & 97,27 & 1,03 & - & 0,43 & 1,7 & - & - \\
\hline Engenheiro Navarro & - & - & 344,93 & 23,5 & - & 4,14 & 29,73 & - & - \\
\hline Espinosa & - & - & 311,12 & 850,69 & 105,92 & - & 87,67 & - & - \\
\hline Francisco Dumont & - & - & 511,23 & 23,29 & 613,81 & 2,32 & 57,37 & - & - \\
\hline Francisco Sá & - & - & 216,71 & 1109,1 & 276,94 & 0,002 & 168,19 & - & - \\
\hline Fruta de Leite & - & - & 570,28 & 68,92 & - & 24,47 & 29,61 & - & - \\
\hline Gameleiras & 0,97 & - & 164,79 & 1022,63 & - & - & 70,6 & - & - \\
\hline Glaucilândia & - & - & 6,19 & 96,95 & - & - & 5,96 & - & - \\
\hline Grão Mogol & 4,38 & - & 2311,28 & 174,29 & 350,4 & 54,74 & 146,52 & - & - \\
\hline Guaraciama & - & - & 172,03 & 9,45 & 68,63 & 5,19 & 17,96 & - & - \\
\hline Ibiaí & - & - & 197,63 & 278,65 & - & 0,29 & 29,75 & - & - \\
\hline Ibiracatu & 0,13 & - & 204,88 & 76,33 & - & - & 10,2 & - & - \\
\hline Icaraí de Minas & - & - & 41,52 & 264,69 & - & 0,34 & 57,56 & - & - \\
\hline Indaiabira & - & - & 763,99 & 23,97 & - & 16,29 & 33,93 & - & - \\
\hline Itacambira & - & - & 765,9 & 61,8 & 588,81 & 35,94 & 103,61 & - & - \\
\hline Itacarambi & - & 88,28 & 107,15 & 603,1 & - & 1,47 & 116,54 & - & - \\
\hline Jaíba & - & - & - & 1405,97 & - & 0,12 & 47,6 & - & - \\
\hline Janaúba & - & - & - & 1168,12 & - & & 67,6 & - & - \\
\hline Januária & 49,26 & 648,32 & 3895,06 & 922,94 & - & 14,98 & 325,35 & - & 37,94 \\
\hline Japonvar & 0,04 & - & 130,11 & 132,34 & - & 0,43 & 13,19 & - & - \\
\hline Jequitaí & - & - & 348,09 & 282,58 & - & 3,81 & 45,11 & - & - \\
\hline Josenópolis & - & - & 315,37 & 75,17 & - & 9,31 & 19,59 & - & - \\
\hline Juramento & - & - & 31,26 & 222,01 & 31,32 & - & 17,07 & - & - \\
\hline Juvenília & - & - & - & 722,98 & - & 0,89 & 36,03 & - & - \\
\hline Lagoa dos Patos & - & - & 128,5 & 206,46 & - & 1,91 & 18,88 & - & - \\
\hline Lassance & 0,95 & - & 833,16 & 600,75 & 541,72 & 8,07 & 119,18 & - & - \\
\hline Lontra & - & - & 109,28 & 70,03 & - & 0,26 & 7,42 & - & - \\
\hline Luislândia & - & - & 293,27 & 30,28 & - & 0,3 & 10,44 & - & - \\
\hline Mamonas & - & - & 51,73 & 96,56 & - & - & 17,27 & - & - \\
\hline Manga & - & - & 16,65 & 1149,74 & - & 0,26 & 179,8 & - & - \\
\hline Matias Cardoso & - & - & - & 1203,38 & - & - & 139,16 & - & - \\
\hline Mato Verde & - & - & 30,52 & 167,78 & 44,9 & 0 & 30,62 & - & - \\
\hline Mirabela & 1,25 & - & 502,77 & 87,66 & - & 0,29 & 22,48 & - & - \\
\hline Miravânia & 0,16 & 138,04 & 277,13 & 81,89 & - & 0,18 & 14,57 & - & - \\
\hline
\end{tabular}




\begin{tabular}{|c|c|c|c|c|c|c|c|c|c|}
\hline & & & & & & & & \multicolumn{2}{|c|}{ Continuação... } \\
\hline Montalvânia & 3,55 & 50,62 & 629,13 & 434,52 & - & 2,78 & 44,62 & - & - \\
\hline Monte Azul & - & - & 90,65 & 416,91 & 36,68 & - & 59,25 & - & - \\
\hline Montes Claros & - & - & 1346,93 & 1312,61 & - & 2,99 & 134,63 & - & - \\
\hline Montezuma & 2,74 & - & 834,19 & 6,19 & - & 12,14 & 36,34 & - & - \\
\hline Ninheira & - & - & 606,78 & 35,69 & - & 3 & 24,57 & - & - \\
\hline Nova Porteirinha & - & - & - & 22,58 & - & & 5,33 & - & - \\
\hline Novorizonte & - & - & 179,73 & 41,89 & - & 6,65 & 10,49 & - & - \\
\hline Olhos-d'Água & - & - & 1086,29 & 53,57 & 499,77 & 36,5 & 90,81 & - & - \\
\hline Padre Carvalho & - & - & 297,83 & 21,62 & - & 10,81 & 16,89 & - & - \\
\hline Pai Pedro & - & - & - & 395,79 & - & - & 23,61 & - & - \\
\hline Patis & 0,88 & - & 180,71 & 134,96 & - & - & 14,39 & - & - \\
\hline $\begin{array}{l}\text { Pedras de Maria da } \\
\text { Cruz }\end{array}$ & - & - & 34,17 & 830,16 & - & 0,95 & 199,45 & - & - \\
\hline Pintópolis & 0,36 & - & 688,27 & 25,51 & - & 3,56 & 71,21 & - & - \\
\hline Pirapora & - & - & 108,85 & 132,19 & - & 1,96 & 20,37 & - & - \\
\hline Ponto Chique & 0,14 & - & 121,41 & 176,45 & - & 0,24 & 69,29 & - & - \\
\hline Porteirinha & - & - & 126,92 & 751,29 & 56,45 & - & 105,75 & - & - \\
\hline Riachinho & - & 31,45 & 664,41 & 86,7 & 167,21 & 5,48 & 63,85 & - & 8,28 \\
\hline $\begin{array}{l}\text { Riacho dos } \\
\text { Machados }\end{array}$ & - & - & 613,9 & 259,41 & - & 9,17 & 69,69 & - & - \\
\hline Rio Pardo de Minas & 1,7 & - & 2214,75 & 87,42 & 123,67 & 50,38 & 140,99 & - & - \\
\hline Rubelita & - & - & 298,84 & 514,91 & - & 36,04 & 49 & - & - \\
\hline Salinas & - & - & 425,04 & 888,41 & - & 53,95 & 91,69 & - & - \\
\hline $\begin{array}{l}\text { Santa Cruz de } \\
\text { Salinas }\end{array}$ & - & - & 242,88 & 140,35 & - & 11,18 & 23,05 & - & - \\
\hline Santa Fé de Minas & 6,31 & 14,35 & 1566,8 & 127,86 & 3,37 & 6,56 & 104,15 & 25,77 & - \\
\hline $\begin{array}{l}\text { Santo Antônio do } \\
\text { Retiro }\end{array}$ & - & - & 626,89 & 8,54 & 32,67 & 16,7 & 34,31 & - & - \\
\hline São Francisco & 1,64 & - & 1232,94 & 781,02 & - & 5,39 & 225,46 & - & - \\
\hline São João da Lagoa & 0,92 & - & 500,86 & 167,77 & - & 2,78 & 35,57 & - & - \\
\hline São João da Ponte & 2,45 & - & 231,42 & 904,3 & - & 0,01 & 51,21 & - & - \\
\hline $\begin{array}{l}\text { São João das } \\
\text { Missões }\end{array}$ & - & 97,16 & 135,95 & 241,06 & - & 0,22 & 17,86 & - & - \\
\hline São João do Pacuí & - & - & 149,89 & 104,76 & - & 0,27 & 15,56 & - & - \\
\hline São João do Paraíso & - & - & 998,53 & 55,71 & - & 13,67 & 54,85 & - & - \\
\hline São Romão & 9,11 & - & 1510,55 & 44,68 & 4,18 & 3,66 & 154,87 & 69,5 & \\
\hline $\begin{array}{l}\text { Serranópolis de } \\
\text { Minas }\end{array}$ & - & - & 96,12 & 220,12 & 79,93 & 2,17 & 47,82 & - & - \\
\hline Taiobeiras & - & - & 602,81 & 155,27 & - & 13,08 & 38,12 & - & - \\
\hline Ubaí & - & - & 196,03 & 304,63 & - & 0,41 & 41,74 & - & - \\
\hline Urucuia & 18,14 & 40,47 & 1072,66 & 34,36 & - & 7,75 & 67,33 & - & 56,43 \\
\hline $\begin{array}{l}\text { Vargem Grande do } \\
\text { Rio Pardo }\end{array}$ & - & - & 350,98 & 11,23 & - & 6,98 & 17,14 & - & - \\
\hline Várzea da Palma & 0,94 & - & 367,85 & 544,65 & 14,24 & 2,45 & 78,78 & - & - \\
\hline Varzelândia & - & - & 37,26 & 523,75 & - & 0,11 & 20,62 & - & - \\
\hline Verdelândia & - & - & - & 879,81 & - & - & 30,83 & - & - \\
\hline Total & 233,69 & 2670,01 & 48169,15 & 28346,18 & 4510,89 & 681,38 & 5875,53 & 103,63 & 372,55 \\
\hline
\end{tabular}

Fonte: Imagens Landsat 8, 2015; Imagens WorldView-II, 2015; Google Earth, 2015; Laboratório de Geoprocessamento, 2017.

Mediante associação das fitofisionomias do Cerrado do Norte de Minas Gerais com o clima, relevo, a pedologia e a hipsometria, constatou-se que o Cerradão compreende áreas que vão desde 495 a 922 metros de altitude, no entanto apresenta $76 \%$ de sua área total em intervalos que variam entre 750 a 835 metros (SRTM, 2000). Inserido inteiramente no clima semiúmido, o 
Cerradão compreende Neossolos Litólicos, Latossolo Vermelho-Amarelo e Cambissolos, no geral são solos oriundos de processos pedogenéticos como agradação, ferralitização e ferruginação, em que ocorre a dessilicação e/ou oxidação do ferro presente no solo. Esta fitofisionomia é encontrada em zonas de Chapadas da bacia do rio São Francisco.

O Cerrado sentido restrito predomina em altitudes intermediárias do semiúmido e semiárido, uma vez que apresenta 68\% entre 620 a 911 metros (SRTM, 2000). A pedologia é compreendida por solos Litólicos, Aluviais, Plintossolo, Podzólico (Vermelho-Escuro, VermelhoAmarelo plíntico e Vermelho-Amarelo) e Latossolo (Vermelho-Escuro, Amarelo e VermelhoAmarelo) (CPRM, 2009; IBGE, 2010). Sua ocorrência dá-se em áreas planas ou levemente onduladas da bacia do rio São Francisco, Pardo e Jequitinhonha.

O Campo Rupestre apresenta predominância de áreas em altitudes superiores a 900 metros de altitude, no entanto, cerca de 32\% localizam-se em áreas inferiores a 900 metros, tais como nos municípios de Buritizeiro e Riachinho. Inserido completamente no semiúmido, o Campo Rupestre apresenta solos do tipo Podzólico (Vermelho-Escuro, Vermelho-Amarelo) e Latossolo VermelhoAmarelo (CPRM, 2009; IBGE, 2010), concentrando em áreas da Serra do Espinhaço.

A Mata Seca localiza-se em diferentes altitudes do semiúmido e semiárido, sendo que cerca de 50\% de suas áreas estão situadas em altitudes inferiores a 590 metros, ou seja, predomina em baixas altitudes (SRTM, 2000). Os solos de sua área de ocorrência são denominados de Vertissolo, Podzólico (Vermelho-Escuro, Vermelho-Amarelo plíntico e Vermelho-Amarelo), Plintossolo e Latossolo Amarelo (CPRM, 2009; IBGE, 2010). No geral, esta fitofisionomia é encontrada em Fundos de Vale e em áreas com maior dissecação do relevo.

As Veredas são encontradas em altitudes compreendidas entre 462 a 1.103 metros. Destaca-se que suas altitudes variam entre 462 a 760 metros na margem esquerda do rio São Francisco e na margem direita esta fitofisionomia situa-se entre 761 a 1.103 metros (SRTM, 2000). Os solos desta fitofisionomia são predominantemente os Gleissolos e Organossolos, que são solos característicos de ambientes saturados por água, a matéria orgânica não é totalmente decomposta, o ferro é reduzido em função das condições anaeróbicas. O relevo em que as Veredas estão inseridas são em áreas planas, onde os vales ainda não estão encaixados.

Inseridos no semiúmido, o Campo Limpo situa-se entre 502 a 551 metros e o Campo Sujo entre 565 a 857 metros (SRTM, 2000). O Campo é compreendido apenas por Areias Quartzosas, enquanto o Campo Sujo além das Areias Quartzosas, também é encontrado em áreas de solos Litólicos, Cambissolos e Latossolo Vermelho-Amarelo (CPRM, 2009).

A Mata Ciliar e Mata de Galeria estão situadas em Fundos de Vale do semiúmido e semiárido. Sua ocorrência são em solos denominados Planossolos, Vertissolos, Cambissolos e Latossolos (CPRM, 2009; IBGE, 2010). Conforme Ribeiro e Walter (1998) as áreas de Mata Ciliar 
apresentam dimensões que raramente ultrapassam 100 metros, são mais densas e altas que a Mata de Galeria, que por sua vez, apresentam dimensões menores e situam-se em áreas de topografias acidentadas.

É importante destacar, que foi identificado uma área de $3.160,87 \mathrm{~km}^{2}$ com resposta espectral de Floresta Estacional Semidecidual (FES). No entanto, não a identificamos neste mapeamento, pois este trabalho foi fundamentado na classificação fitofisionômica de Ribeiro e Walter (1998). Nesse sentido, a Floresta Estacional Semidecidual foi agregada à classe Cerrado sentido restrito no mapeamento das fitofisionomias do Cerrado.

Portanto, constata-se, a partir dessa correlação entre as características naturais (clima, relevo, pedologia e hipsometria) com as fitofisionomias do Cerrado norte-mineiro que o Cerradão, Cerrado sentido restrito, Veredas e o Campo Sujo predominam em altitudes intermediárias, principalmente em zonas de chapadas. O Campo Limpo, a Mata Seca, a Mata Ciliar e a Mata de Galeria situam-se em baixas altitudes, especificamente em areias quartzosas dos Fundos de Vale. O Campo Rupestre concentra-se em altitudes elevadas, apresenta como principal característica, afloramentos rochosos do semiúmido.

\section{CONSIDERAÇÕES FINAIS}

Com o mapeamento do Cerrado no Norte de Minas Gerais, constatou-se que o Cerrado sentido restrito $(34,63 \%)$ e a Mata Seca $(20,38 \%)$ são as fitofisionomias com as maiores áreas. As características de suas áreas de ocorrência diferem, pois o Cerrado sentido restrito ocorre em áreas aplainadas e mais elevadas, enquanto a Mata Seca ocorre em Fundos de Vale e em áreas com maior declividade.

O Campo Rupestre (3,24\%), Cerradão $(1,92 \%)$ e a Mata Ciliar $(4,22 \%)$ apresentam percentuais intermediários e também se diferem quanto a sua localização geográfica. Aproximadamente $68 \%$ das áreas de Campo Rupestre são encontradas em altitudes mais elevadas (900 a 1717 metros). Esta fitofisionomia tem como principal característica a presença de afloramentos rochosos. O Cerradão se concentra no oeste da região e há na sua área de ocorrência, áreas inferiores a 922 metros de altitude. Por sua vez, a Mata Ciliar, acompanha os canais fluviais da região, ocupando as maiores áreas no entorno do rio São Francisco.

As menores áreas são compostas pela Mata de Galeria (0,49\%), Campo Sujo (0,27\%), Veredas $(0,17 \%)$ e o Campo Limpo (0,07\%). A Mata de Galeria e as Veredas acompanham o canal fluvial de pequena dimensão. O Campo Sujo (565 a 857 metros) e o Campo Limpo (502 a 551 metros) concentram-se em alguns municípios e são encontrados em altitudes distintas, embora não elevadas. 
No geral, as fitofisionomias apresentam predominância em altitudes distintas do semiúmido. Em baixas altitudes ( < 600 m) têm-se o Campo Limpo, a Mata Seca, a Mata Ciliar e a Mata de Galeria. O Cerradão, o Cerrado sentido restrito, as Veredas e o Campo Sujo predominam em altitudes intermediárias (600 - 900 m), o Campo Rupestre situa-se em altitudes elevadas ( > 900 $\mathrm{m})$.

Embora possuam quantidade de áreas distintas, ambas as fitofisionomias apresentam solos Litólicos e Podzólicos, Cambissolos e Latossolos. A exceção perfaz somente o Campo Limpo que é encontrado em Areias Quartzosas e as Veredas que apresentam Gleissolos e Organossolos. Constata-se, que a hipsometria e a forma do relevo são os principais condicionadores da distribuição espacial das fitofisionomias do Cerrado norte-mineiro.

Desta feita, o mapeamento das fitofisionomias do Cerrado, gerado por meio do sensoriamento remoto, poderá apresentar contribuições como o conhecimento da biodiversidade regional e auxiliar na conservação do Cerrado.

\section{REFERÊNCIAS}

AB’SÁBER, A. N. Os Domínios de Natureza no Brasil: Potencialidades Paisagísticas. 1. ed. São Paulo: Ateliê Editorial, 2003. 159p.

CPRM, Serviço Geológico do Brasil. 2009. Disponível em:<http://www.cprm.gov.br/>. Acesso em: 18 jan. 2018.

DIGITAL GLOBE. WorldView-II. 2017. Disponível em: <https://www.digitalglobe.com /about/our-constellation>. Acesso em: 18 jan. 2018.

EMBRAPA. Empresa Brasileira de Pesquisa Agropecuária. Bioma Cerrado: Vegetação Campestre. Brasília, 2018. Disponível em: $<$ http://www.agencia.cnptia.embrapa.br/ Agencia16/AG01/arvore.html>. Acesso em: 05 jan. 2018.

FLORENZANO, T. A. Iniciação em Sensoriamento Remoto. 3. ed. São Paulo: Oficina de Textos, 2011. 128p.

IBGE. Instituto Brasileiro de Geografia e Estatística. 2004. Disponível em: <http://www.ibge. gov.br/>. Acesso em: 05 jan. 2018.

. Instituto Brasileiro de Geografia e Estatística. 2010. Disponível em: <http://www.ibge. gov.br/>. Acesso em: 05 jan. 2018.

KLING, C. A.; MACHADO, R. B. Conservation of the Brazilian Cerrado. Conservation Biology, v. 19, n. 3, p. 707-713, 2005.

PINHO, C. M. D.; UMMUS, M. E.; NOVACK, T. Extração de feições urbanas em imagens de alta resolução espacial a partir do estudo do comportamento espectral dos alvos. Revista Brasileira de Cartografia, Uberlândia, v. 63, n. 4, p. 439-448, 2011. 
PONZONI, F. J.; ShIMABUKURO, Y. E.; KUPLICH, T. M. Sensoriamento Remoto da Vegetação. 2. ed. São Paulo: Oficina de Textos, 2012. 176p.

RIBEIRO, J. F.; WALTER, B. M. T. Fitofisionomias do Bioma Cerrado. In: SANO, S. M.; ALMEIDA, S. P.; RIBEIRO, J. F. (Orgs.). Cerrado: Ecologia e Flora. Brasília: Embrapa Informação Tecnológica, 1998. p. 87-166.

ROSA, R. Introdução ao Sensoriamento Remoto. 7. ed. Uberlândia: EDUFU, 2009. 264p.

ROSENDO, J. S. Índices de Vegetação e Monitoramento do Uso do Solo e Cobertura Vegetal Na Bacia do Rio Araguari - MG - Utilizando Dados do Sensor Modis. 2005. 152 f. Dissertação (Mestrado em Geografia) - Instituto de Geografia, Universidade Federal de Uberlândia, Uberlândia, 2005.

SANO, E. E.; ROSA, R.; BRITO, J. L. S.; FERREIRA, L. G.; Mapeamento Semidetalhado do Uso da Terra do Bioma Cerrado. Pesquisa Agropecuária Brasileira, Brasília, v. 43, p. 153-156, 2008.

SRTM. Shuttle Radar Topography Mission. 2000. Disponível em:<https://www.cnpm.embrapa.br /projetos/relevobr/download/>. Acesso em: $20 \mathrm{dez} .2017$.

WALTER, B. M. T. Fitofisionomias do Bioma Cerrado: Síntese Terminológica e Relações Florísticas. 2006. 374 f. Tese (Doutorado em Ecologia) - Instituto de Ciências Biológicas, Universidade de Brasília, Brasília, 2006.

Trabalho enviado em 19/02/2019

Trabalho aceito em 13/07/2019 